\title{
Health and safety implementation in Indonesia and risk of COVID-19
}

\author{
Adithya Sudiarno ${ }^{1}$, Sri Indriyani Diartiwi ${ }^{2}$, Ratna Sari Dewi ${ }^{3}$, M. Rizqi Zulqornain ${ }^{4}$, \\ Maria Susanti ${ }^{5}$, Edwin Hermawan ${ }^{6}$, Dedy ${ }^{7}$, Syamsul Arifin ${ }^{8}$, Reni Wulansari', \\ Reza Aulia Akbar ${ }^{10}$, Muhammad Hendrawan Hidayat ${ }^{11}$, Rico Feryanto ${ }^{12}$ \\ 1,2,3,10,11,12 Industrial and Systems Engineering Department, Institut Teknologi Sepuluh Nopember, Indonesia \\ ${ }^{4}$ PT. ZFAG Aftermarket Jakarta, Indonesia \\ ${ }^{5}$ Regional Manpower and Transmigration Office of East Java Province, Indonesia \\ ${ }^{6}$ Ministry of Energy and Mineral Resources, Indonesia \\ ${ }^{7}$ PT. Pembangkit Jawa Bali (PJB), Indonesia \\ ${ }^{8}$ Pertamina Hulu Indonesia (PHI), Indonesia \\ ${ }^{9} \mathrm{PT}$. Telekomunikasi Indosesia (Persero) Tbk, Indonesia
}

\begin{tabular}{l}
\hline \hline Article Info \\
\hline Article history: \\
Received Aug 27, 2020 \\
Revised Nov 28, 2020 \\
Accepted Jan 2, 2021 \\
\hline
\end{tabular}

\section{Keywords:}

COVID-19

Health safety environment

Pandemic

Safety model canvas

\begin{abstract}
The COVID-19 pandemic impacted the socio-economic sectors since the end of 2019. Indonesian's Government issued the large-scale social restrictions policy to limit the industrial activities. This study aimed to investigate the difference of the health, safety, and environment (HSE) implementations among Indonesian companies, before and during the disruption risk of COVID-19 pandemic according to the use of personal protective equipment (PPE). It used a random sampling, involved 1,027 workers from various sectors of Indonesian companies. Hypothesis tests used are ANOVA and ttest method. The level of HSE compliance changed quite significantly when the COVID-19 outbreak emerged. The results explained, there is no significant difference in HSE compliance based on company location, company risk level, and position of a respondent in the company. However, there is a significant difference between companies that have a HSE division and a HSE Management System certificate with the company who did not have any. The recommendations of HSE improvement formulated using a Safety Model Canvas and a Focus Group Discussion conducted to convey the jazz scenario in the next normal. This study suggests the priority order for HSE improvement strategy in a company is commitment, responsibility, engagement and involvement, leadership, competence, information and communication, to organizational learning.
\end{abstract}

This is an open access article under the CC BY-SA license.

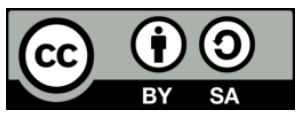

Corresponding Author:

Adithya Sudiarno

Department of Industrial and Systems Engineering

Institut Teknologi Sepuluh Nopember, Indonesia

Email: adithya.sudiarno@gmail.com

\section{INTRODUCTION}

At the end of 2019, a new pneumonia case emerged from Wuhan in China, which quickly spread to more than 212 countries. This outbreak is called Coronavirus Disease 2019 (COVID-19). In general, it spreads through fluids that come from coughing, sneezing, and kissing [1]. On March 2020, the world health organization (WHO) announced COVID-19 as a pandemic [2]. If the COVID-19 pandemic situation continues and deteriorating, the Congressional Research Service estimated that world economic growth in 
2020 would decline by 6-7.6\% [3]. Not only does this impact the economic sector, but this situation also affects the society [4]. In this situation, most countries in the world applied lockdown in their country.

There were 33,076 positive cases of COVID-19 on June 9, 2020 in Indonesia with a mortality rate of $5.81 \%$, which is the second-highest rank in the Asia Pacific [5]. To cope in this situation, Indonesian's Government implements several policies such as the Regulation of the Health Minister of the Republic Indonesian Number 9 of 2020 concerning on large-scale social restrictions. This regulation suspend various sectors of economic activities and freed some sectors from the suspension, such as the health service sector, food needs, and several companies related to other basic needs, to fulfill the basic needs and supply chains for the society [6]. COVID-19 is one of biological hazards in the workplace that can result in threats to the health and safety of workers. Therefore, companies that continue to operate are required to comply with the health protocol recommended by the WHO through the Minister of Industry Circular Number 4 of 2020 as a form of implementing the new normal in avoiding the transmission of COVID-19. The other forms of risk identified in a company are operational risk and disruption risk. Based on the international labor organization (ILO), $88 \%$ of work accidents are caused by unsafe acts, $10 \%$ caused by unsafe conditions, and $2 \%$ caused by unforeseeable factors [7].

Work accident that occurs caused by the unsafe acts or conditions is related to operational risk, where the accident involves workers and daily operational processes. This operational risk control is the domain of HSE discipline enforcement in a company. Disruption risk can take various forms, such as natural disasters, terrorist attacks, and else which expected to have a negative impact [8]. This term is known-well in the field of supply chain, where while disruption occurs in a part of the chain, the outcome could have a more severe impact on the other parts [9]. Companies need to integrate disruption risk management into operational risk management [8]. Likewise in HSE management in a company. As a result of the COVID-19 that is spread easily and it is assumed as an unforeseeable factor, the disruption risk that occurs due to COVID-19 notables for the HSE division and company workers in addition to existing operational risks. It also could hinder production performance and even disruptively shut down production. Thus, numerous conditions of implementing health and safety in companies in Indonesia is predicted to increase.

During the COVID-19 pandemic, there were several researches about safety published. One of them conducted scientific literature on the Coronavirus. The result explains that an interdisciplinary approach and collective scientific efforts are needed to help understanding and reducing the various safety impacts of the COVID-19 pandemic, in addition to an understanding of the biomedical risks that exist in COVID-19 [10]. Other previous research explained that COVID-19 triggers multi-level stress for drivers that could form behavioral and psychosocial responses that affect their health and safety [11]. In other research, [12] applied clinical operation learning using teleconference platforms due to the impact of the COVID-19 pandemic. Research conducted by [10] also summarized the safety dimensions and shown parts of each dimension based on the compilation of researches published during the COVID-19. There are ten dimensions, including blood safety, surgery, occupational safety of healthcare workers, and else. The safety dimensions in previous researches focused more on the medical subject area. There was no research focuses on analyzing the effect of disruption risk of COVID-19 on increasing safety awareness in companies.

With the disruption risk of COVID-19, an unforeseeable factor that can endanger workers, this research focuses on investigating whether there is an increase (or not) in health and safety or HSE implementation in companies according to the use of PPE in Indonesia using surveys and statistic tests. The measurement used is the HSE implementation, which is not only based on compliance with COVID-19 itself but also related to the compliance concerning operational risk. The recommendations from the results acquired is formulated using the safety model canvas (SMC) through focus group discussion (FGD) with cross-sectoral safety experts, so that lessons learned from the existence of COVID-19 disruption risk are obtained. Suppose this study proves that there has been an increase in HSE compliance in companies in Indonesia, we hope that disruption risk of COVID-19 will become a momentum for "embracing next normal" in the implementation of HSE in companies in Indonesia.

\section{RESEARCH METHOD}

This study employed a cross-sectional study method with a random sampling survey technique involved workers from various sectors of companies in 34 provinces in Indonesia. The survey used online questionnaire and spread through social media applications such as Facebook, Instagram, WhatsApp, and Telegram randomly. This study uses primary data obtained from the survey by exploring workers' perceptions of HSE compliance in the company before and during the COVID-19 pandemic, both related to the utilization of PPE to minimize operational risk and disruption risk for COVID-19. Supporting data collected includes the risk level of the company, worker's job title, island/archipelago regions, the ownership of the HSE division, and the ownership of the HSE management system (HSEMS) certificate in the 
company. Next, the researchers performed a parametric statistic tests to prove the hypothesis from the data collected using the one-way ANOVA and t-test with a confidence level of $95 \%$. The results of the statistic test then interpreted and analyzed based on literature studies. The recommendations obtained from the survey were formulated into the SMC and discussed through FGD with cross-sectoral safety experts from academicians, government, and business to get a priority order of health and safety aspects related to forces to improve safety atmosphere in Indonesia.

\section{RESULTS AND DISCUSSION}

\subsection{Respondent demographics}

Based on the results of the survey, the amount of respondents obtained is 1,049 respondents. A screening carried out to eliminate the duplication of data and that the results become 1,027 respondents. Table 1 summarizes the demographics of the respondents based on the several categories.

\begin{tabular}{|c|c|c|}
\hline Jo. & Category & Percentage \\
\hline \multirow[t]{7}{*}{1} & Respondent's location & \\
\hline & Sumatera Island & $8.07 \%$ \\
\hline & Java Island & $68.59 \%$ \\
\hline & Bali-Nusa Tenggara Arch. & $4.71 \%$ \\
\hline & Kalimantan Island & $7.40 \%$ \\
\hline & Sulawesi Island & $8.84 \%$ \\
\hline & Maluku-Papua Archipelago & $2.40 \%$ \\
\hline \multirow[t]{4}{*}{2} & Risk level of the company & \\
\hline & Low & $40.60 \%$ \\
\hline & Medium & $10.60 \%$ \\
\hline & High & $48.80 \%$ \\
\hline \multirow[t]{5}{*}{3} & Respondent's job title & \\
\hline & Staff & $58.67 \%$ \\
\hline & Supervisor & $21.20 \%$ \\
\hline & Manager/general manager & $17.35 \%$ \\
\hline & $>$ General manager & $2.77 \%$ \\
\hline \multirow[t]{3}{*}{4} & Respondent's scope of work & \\
\hline & HSE division & $21.13 \%$ \\
\hline & General division (other than HSE) & $78.87 \%$ \\
\hline \multirow[t]{3}{*}{5} & $\begin{array}{l}\text { Ownership of the HSE division in the } \\
\text { company }\end{array}$ & \\
\hline & Yes & $69.09 \%$ \\
\hline & No & $30.91 \%$ \\
\hline \multirow[t]{3}{*}{6} & $\begin{array}{l}\text { Ownership of the HSEMS cert. in the } \\
\text { company }\end{array}$ & \\
\hline & Yes & $68.93 \%$ \\
\hline & No & $31.07 \%$ \\
\hline
\end{tabular}

For the category of respondent's location based on island/archipelago, that Java Island has the highest number of respondents, namely $68.59 \%$. It is because Java Island is the center of Indonesia's economy. In 2019, around 59\% of Indonesia's GDP was a contribution from Java Island [13]. The majority of respondents came from companies with a high-risk level, amounting to $48.80 \%$, namely the corporate sector such as hospitals and medical services, power plants, construction industry, to manufacture company. Respondents are workers in companies with various job titles, ranging from staff to the above of general manager. The highest percentage is at the middle-low management level, namely staff and supervisors. Next is the respondent's scope of work that came from the HSE field for $21.13 \%$. It resulted in $69.09 \%$ of the respondent's workplace already have a HSE division and $68.93 \%$ of the companies where the respondents worked already have a HSEMS certificate.

\subsection{Distribution of health and safety compliance using PPE}

The main variable used in measuring change in the level of HSE implementation before and during the COVID-19 pandemic is HSE compliance according to the use of PPE. Before and during the COVID-19 pandemic, workers' HSE compliance identified from the use of standard PPEs such as safety shoes, safety helmets, safety gloves, mask, and other relevant PPE. The distribution of HSE compliance before and during the COVID-19 pandemic is presented in the Table 2. 
Table 2. HSE compliance levels distribution of using PPE in the company

\begin{tabular}{|c|c|c|c|c|c|c|}
\hline \multirow{3}{*}{ Category } & \multicolumn{5}{|c|}{ Survey results } & \multirow{3}{*}{ Mean } \\
\hline & \multicolumn{5}{|c|}{ Respondent's level of compliance } & \\
\hline & Very obedient & Obedient & Quiet obedient & Disobedient & Very disobedient & \\
\hline Before the COVID-19 pandemic & $10.81 \%$ & $30.09 \%$ & $36.71 \% *$ & $19.28 \%$ & $3.12 \%$ & 3.26 \\
\hline During the COVID-19 pandemic & $44.89 \% *$ & $44.79 \%$ & $8.76 \%$ & $1.46 \%$ & $0.10 \%$ & 4.33 \\
\hline Delta & $34.08 \% \uparrow$ & $14.70 \% \uparrow$ & $27.95 \% \downarrow$ & $17.82 \% \downarrow$ & $3.02 \% \downarrow$ & \\
\hline
\end{tabular}

Table 2 shows that there was an increase in the category of very obedient and obedient, and a decrease in the other categories. The highest increase occurred at the very obedient, namely $34.08 \%$. Before the COVID-19 pandemic, majority of respondent compliance level of using PPEs is about $36.71 \%$ in quiet obedient level. While during the COVID-19 pandemic, the compliance level is mainly in very obedient level for $44.89 \%$. This difference will be observed further using paired samples t-test that is shown in Table 3.

Table 3. Test of difference in HSE compliance levels of using PPE in the company

\begin{tabular}{|c|c|c|c|c|c|c|}
\hline \multicolumn{7}{|c|}{ Paired samples t-test with confidence level of $95 \%$} \\
\hline \multirow{2}{*}{ Pair } & \multicolumn{3}{|c|}{ Paired differences } & \multirow{2}{*}{$\mathrm{t}$} & \multirow{2}{*}{$\mathrm{df}$} & \multirow{2}{*}{ Sig. (2-tailed) } \\
\hline & Mean & Std. deviation & Std. error mean & & & \\
\hline Before-during the COVID-19 pandemic & -1.07 & .98 & .031 & -34.85 & 1026 & .000 \\
\hline
\end{tabular}

The result of hypothesis testing in Table 3 is carried out with the initial hypothesis that the level of HSE compliance before and during the COVID-19 pandemic has no significant difference with confidence level of $95 \%$. The result shows that the Sig. (2-tailed) is less than 0.05 (error rate), so the initial hypothesis is rejected. It assumed that there is a significant difference between the levels of compliance in HSE implementation at various companies in Indonesia when the COVID-19 emerged. Before the COVID-19 pandemic, the majority respondents said they were quite obedient. During the COVID-19 pandemic, the result became very obedient. This indicates the workers are becoming more aware of the importance of implementing HSE during the COVID-19 pandemic occurred in Indonesia. This awareness triggered by the existence of COVID-19 disruption risk, which is an unforeseeable factor related to the risk at the company. The result of this study is in line with the research conducted by [14], who succeeded in proving that the proper and correct use of PPEs could reduce the possibility of COVID-19 transmission in the workplace. Thus, the existence of disruption risk makes workers more aware and obedient in implementing health and safety to minimize operational risk and reduce the risk of the possibility of contracting the disease.

\subsection{Health and safety increase in compliance based on respondent category}

The survey results are being analyzed further after being tested in the hypothesis testing using the one-way ANOVA and the independent t-test. The hypothesis test used the increase in HSE compliance in the company as the dependent variable and the respondent category as the independent variable. The ANOVA method used for data that had more than two samples, while the independent t-test for data that had two notrelated samples. The result of ANOVA is shown in the Table 4 and for independent t-test is in the Table 5.

Table 4. Recapitulation of ANOVA test results for HSE compliance

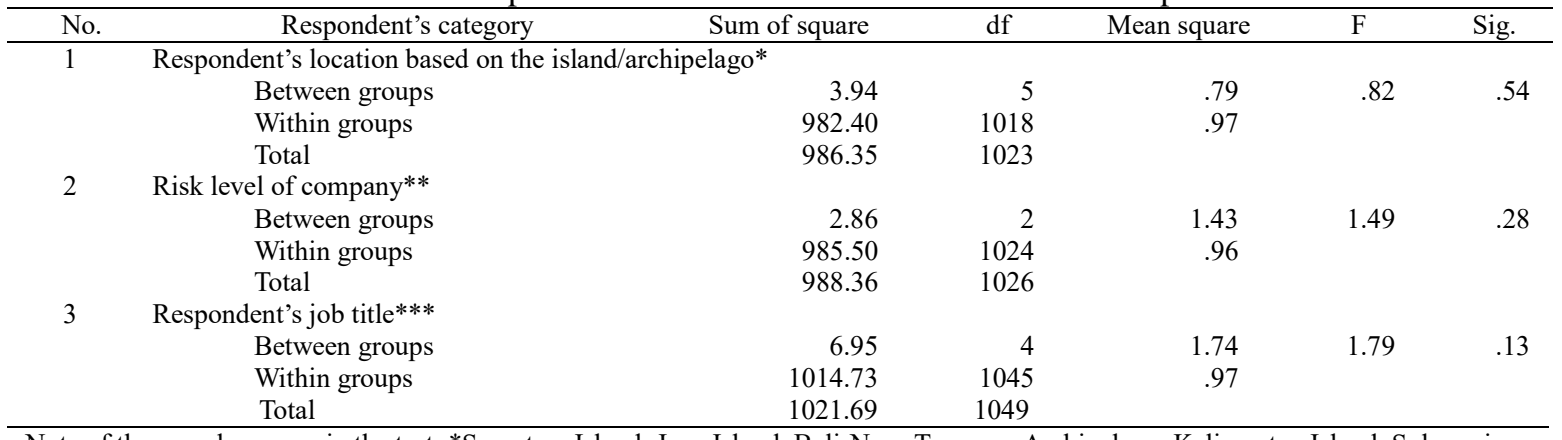

Note of the samples group in the test: *Sumatera Island, Java Island, Bali-Nusa Tenggara Archipelago, Kalimantan Island, Sulawesi Island, and Maluku-Papua Archipelago; **Low, medium, high; ***staff, supervisor, manager/general manager, and above the general manager 
Table 5. Recapitulation of independent t-test results for HSE compliance

\begin{tabular}{|c|c|c|c|c|c|c|c|}
\hline \multirow{2}{*}{ Category } & \multicolumn{2}{|c|}{$\begin{array}{c}\text { Levene's test for } \\
\text { equality of variances }\end{array}$} & \multicolumn{5}{|c|}{ T-test for equality of means } \\
\hline & $\mathrm{F}$ & Sig. & $\mathrm{t}$ & df & Sig. (2-tailed) & $\begin{array}{c}\text { Mean } \\
\text { difference }\end{array}$ & $\begin{array}{l}\text { Std. Error } \\
\text { difference }\end{array}$ \\
\hline Ownership of the HSE division & \multirow{4}{*}{8.06} & \multirow{3}{*}{.005} & & & & & \\
\hline Equal variances assumed & & & 3.70 & 851 & .000 & .31 & .08 \\
\hline Equal variances not assumed & & & 3.45 & 245.91 & .001 & .31 & .09 \\
\hline \multicolumn{7}{|l|}{ Ownership of the HSE Management } & \\
\hline System (HSEMS) certificate & \multirow{3}{*}{21.39} & \multirow{3}{*}{.000} & & & & & \\
\hline Equal variances assumed & & & 2.73 & 481 & .007 & .12 & .05 \\
\hline Equal variances not assumed & & & 2.68 & 364.03 & .008 & .12 & .05 \\
\hline
\end{tabular}

In the ANOVA hypothesis test, the confidence level used was $95 \%$ with the initial hypothesis that there is no significant difference in the increase in HSE compliance between more than two samples tested. When the data has a Sig. value that is greater than the error level or 0.05 , the initial hypothesis is accepted and vice versa. Table 4 shows that Sig. value is greater than 0.05 for all respondent's categories. It concluded that there is no significant difference in the increase in HSE compliance of the various companies surveyed based on island/archipelago location, company risk level, and respondent's job title. Companies in the islands of Sumatra, Java, Bali-Nusa Tenggara, Kalimantan, Sulawesi, and Maluku-Papua Islands are aware that the COVID-19 pandemic can spread to all locations in Indonesia so that workers from various companies are motivated to improve the compliance in HSE implementation. Companies at any risk levels, such as low, medium, and high, are showed increases in the HSE implementation in the same margin. They are aware that the disruption risk occur during the COVID-19 pandemic can be risky for all workers in the company regardless of the level of risk in each industry. The labor are assigned to a more dangerous work environment than the managerial level. A hazardous work environment can affect workers' conditions so that the company proceeded to implement a more disciplined HSE [15]. However, the results indicated that workers from all management level experienced an increase in HSE compliance during the COVID-19 pandemic. The results are in line with previous research, [16] stated that the risks caused by the pandemic disease are not only applied to certain positions, but any job title could receive various impacts.

The independent t-test used a 95\% confidence level. The initial hypothesis is there is no significant difference in the increase of HSE compliance in the two samples tested. In Table 5, it presents the data based on the ownership of the HSE division and HSEMS certificate. In the third column, the Sig. value is smaller than 0.05. It shows that both data were not homogeneous. To find out the results of hypothesis testing, referred to the Sig. (2-tailed) or sixth column in the row of 'equal variances not assumed'. Both data categories had a value below 0.05 , so the initial hypothesis was rejected. It means that there is a significant difference in the increase of HSE compliance in companies that already have a HSE division or HSEMS certificate compared to companies that did not have any. Based on the survey results, it concluded that the average percentage of increase in HSE compliance in companies that already have a HSE division was only $25 \%$, while in companies that did not have it was $32.66 \%$. The average percentage of increase in HSE compliance in companies that have a HSEMS certificate was $24.45 \%$ and the other was $33.23 \%$. It proved that companies which did not have a HSE division or HSEMS certificate had an increase in HSE compliance during the COVID-19 pandemic better than companies that already have any. It is a positive finding because there is a phenomenon that during the pandemic, many companies are starting to realize the importance of the HSE division and HSEMS certification. The projected benefit of this finding is that the number of companies that have HSE division and HSEMS certificate also estimated to increase. Companies that did not have proper HSE management could effect on decreasing the worker's productivity [17]. The increased of compliance in companies that did not have a HSE division or HSEMS certificate during COVID-19 explained that the company was trying to maintain the workers' productivity during a pandemic.

\subsection{Health and safety recommendations}

The existence of disruption risk of COVID-19, as an unforeseeable factor, concluded to be able to provide a positive benefit in the increase in HSE compliance. The shifting in the HSE implementation that occurred in companies in Indonesia indicates an increase in the safety atmosphere. It described by the application of health protocols and the proper use of COVID-19 PPEs in addition to the use of standard PPEs. Previously, companies tended to implement HSE stagnant or inconsistently. Continuous improvement in the company (workplace innovation) in response to a problematic production process influences the HSE implementation [18]. Companies that carry out innovations will tend to be consistent in implementing HSE because they always make improvements and vice versa. Recommendations for improvement on seven 
aspects of health and safety are needed to support the increase in safety atmosphere in the next normal in companies in Indonesia. Based on the survey results the priority order of the aspects are start from commitment with a percentage of $22.67 \%$ followed by responsibility for $19.78 \%$, engagement \& involvement for $18.70 \%$, leadership as much as $15.31 \%$, competence for $10.84 \%$, information and communication for $9.30 \%$, and in the last priority is organizational learning about $3.40 \%$.

It could not be denied that the safety atmosphere in Indonesia is increasing due to the disruption risk of COVID-19. Although this disruption risk will decrease along with the discovery of the COVID-19 vaccine, there are several possible conditions for HSE compliance in the period of the next normal. Figure 1 is a brief illustration of the possibilities that will occur in the next normal.

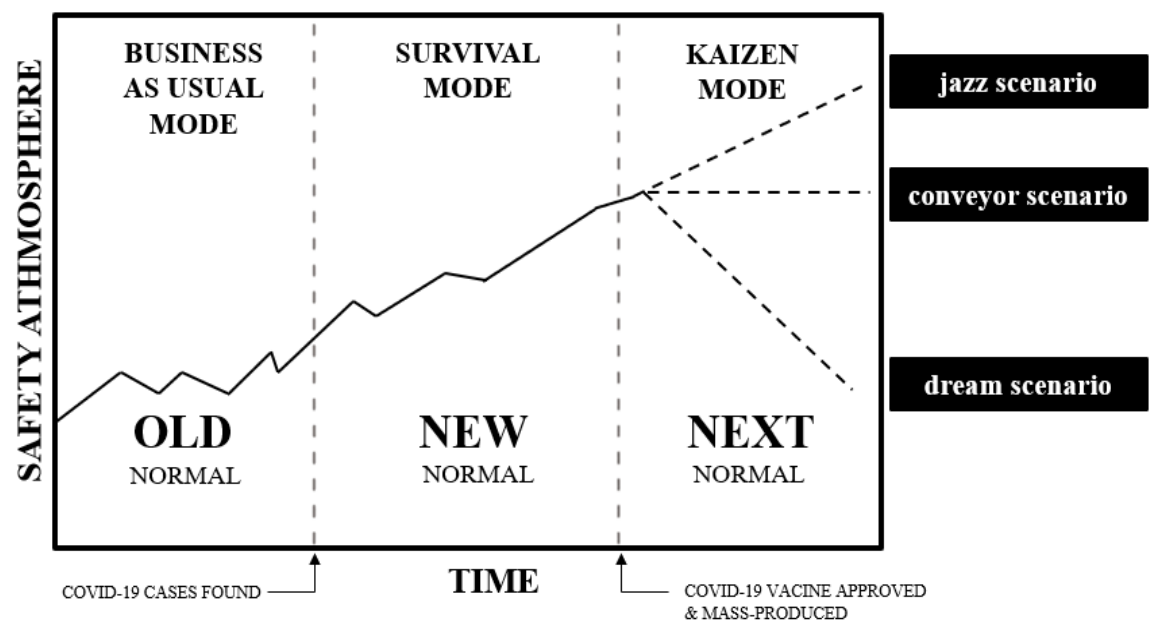

Figure 1. Scenarios of HSE implementation based on COVID-19 pandemic period

There are three possible scenarios for the safety atmosphere condition in the next normal, namely jazz scenario where the safety atmosphere continues to increase significantly, the conveyor scenario where the safety atmosphere is stay the same in the next normal, and the last is the dream scenario where the safety atmosphere is decrease significantly. It is necessary to formulate a general strategy to continuously improve the HSE implementation in various companies in Indonesia to pursue the jazz scenario. Several cross-sectoral safety experts from academicians, government, and businesses have conducted FGD with researchers to formulate general strategies then the results transformed into the safety model canvas (SMC).

SMC is a template developed for safety engineers to formulate a strategy to increase the safety atmosphere regarding the existing conditions of each company. It used the same approach as the business model canvas framework of mind by mapping a condition within the company, which is written on a canvas to conceptualize the right business model for the company $[19,20]$. SMC consists of seven building blocks, in this study is the same as the health and safety aspects, which can be the main aspects of improvement to increase the safety atmosphere in the next normal. The strategy formulation for SMC is based on perceived risk as an input and risk controlled as the output of the canvassing process. Each company has different characteristics that makes the canvassing process vary for each company. To carry out the canvassing process, it could refer to the priority aspects obtained from the results of field observations or assessments.

The following Figure 2 shows the SMC formulated through FGD with safety experts by considering the priority aspects of health and safety in supporting the next normal, which becomes a stage or path in the formulation of improvement strategies at SMC. Generic recommendations to improve the safety atmosphere in Indonesia are designed with consideration to various input during surveys and based on the professional experience of the safety experts.

The first aspect that need to be strengthened is commitment. It can be improved through reengineering the company's business model to implement health and safety as an integral part of the company's vision and mission. Strengthening HSE commitment in a company creates a positive effect on satisfaction and HSE implementation [21]. Without a strong commitment from company, Amponsah-Tawiah and Mensah believe that the workers tend to perform withdrawal behaviors [22]. Thus, it is not surprising that commitment is the first priority aspect that needs to be improved on efforts to improve the safety atmosphere in Indonesia. The second priority is, according to the results, the safety atmosphere can be improved by increasing all employee responsibilities in all managerial lines. A references written by [23] 
stated that the issue of HSE is a shared responsibility for everyone thus must be prioritized. The third aspect is engagement and involvement, which can be improved by increasing the spirit of collaboration among all elements of the division in the company. This recommendation is supported by $[23,24]$ that to reduce the level of work accidents, the cooperation between all parties and engagement between all workers is needed. The fourth priority based on the results of the survey and FGD is the aspect of leadership that can be improved through efforts to strengthen the role of top management to provide a good example and supervise the implementation of HSE policies. According to $[25,26]$, providing support and supervision can be done from top to low management to improve the safety atmosphere in the company. The top management also responsible to maintain the safety and health of work environment including the knowledge of occupational hazards and the commitment to promote the safety implementation in company [27]. The fifth aspect is competence that can be improved through continuous and structured HSE training activities. Based on [28], efforts to increase competence through safety training can directly affect the performance of HSE implementation. Next is the information and communication aspect, which can be improved through the development of a centralized HSE database. Best practices for implementing health and safety in several companies in Europe, according to [29], shows that a centralized HSE information and communication channel can facilitate access to information to pursue the better HSE in their companies. The last aspect of the priority for improving safety atmosphere scale is organizational learning. It can be improved through the provision of facilities that make the sharing knowledge from the successful HSE implementation in the company. Through this organizational learning, companies can learn from experiences of previous success and mistakes, thus companies can adapt and develop the better health-safety methods [30].

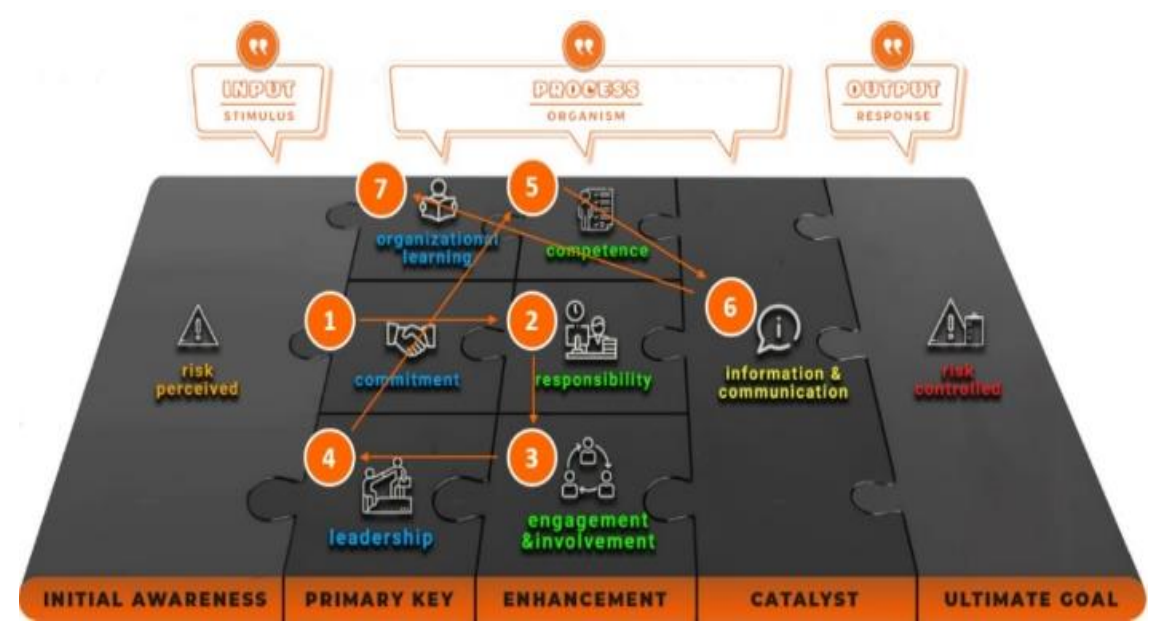

Figure 2. Safety model canvas for improvement recommendation of the safety atmosphere in next normal

\subsection{Limitation}

This study used an online questionnaire spread through social media applications. Total 1,027 respondents were obtained randomly and scattered from all over Indonesia. Nevertheless, this study has several limitations that should be understood. It was a cross-sectional study conducted online to explore workers' perceptions of general HSE compliance (in the use of PPE) at the beginning of the COVID-19 pandemic in Indonesia. There were no data could be obtained regarding accident rate and COVID-19 victims from each company surveyed. The data presented was self-reported depending on the respondents' honesty and objectivity to give feedback. This condition may result in information bias. Despite that, this study provided valuable information regarding the risk disruption presence toward HSE compliance and the strategy to maintain the safety atmosphere in the next normal.

\section{CONCLUSION}

The COVID-19 pandemic has impacted the world, including Indonesia. Generally, HSE implementation in various companies in Indonesia has been increasing in compliance, especially in the use of PPEs, between before and during the COVID-19 pandemic. It is proved from the results of the t-test statistic test. Whereas in HSE compliance related to the company location, company risk level, and worker's position level, based on the ANOVA statistic tests, there were no significant differences, means the increases that 
occurred in each category were on the same margin. Based on the t-test statistic test, there was a significant difference in which companies that did not have a HSE division or a HSEMS certificate experienced a higher increase than companies that already have any. This increase indicates that the safety atmosphere is increasing due to the disruption risk of the COVID-19 pandemic as an unforeseeable factor. It allowed several scenarios to occur in the next normal, where the ideal condition is the jazz scenario. Based on the survey data and FGD with cross-sectoral safety experts, the recommendation to maintain the safety atmosphere is obtained by employed the SMC. The priority order of aspects that need to be improved starts from the commitment, responsibility, engagement and involvement, leadership, competence, information and communication, to organizational learning.

\section{ACKNOWLEDGEMENTS}

This paper received contributes from several categories of safety experts. The safety experts from the academicians are Taufik Nur, Shofa Aulia A., Wiediartini, Tranggono, and Purwati. From the government are Warga Bagus P., Rainir Akbar, and Z. F. Arif B. And from the business are Guntur Suryaning Hadi, Bagus Rachmadona, Mohammad Izzuddin Alfannani, Mohamad Chairuddin Yunus, Hendy Nugroho, Aris Dwi Andrianto, Ibnu Hazmin Nawadir, Naim Hamid, Dwi Bagus Harso W., and Mohammad Setyo Puji Raharjo.

\section{REFERENCES}

[1] Kumar, D., Malviya, R., and Sharma. PK., "Corona Virus: A Review of COVID-19," Eurasian Journal of Medicine and Oncology, vol. 4, no. 1, pp. 8-25, 2020, doi: http://doi.org/10.14744/ejmo.2020.51418.

[2] WHO, "Rolling updates on coronavirus disease (COVID-19)," World Health Organization, 2020. [Online]. Available: https://www.who.int/emergencies/diseases/novel-coronavirus-2019/events-as-they-happen.

[3] Jackson, JK, et al., "Global Economic Effects of COVID-19," Congressional Research Service, 2020. [Online]. Available: https://fas.org/sgp/crs/row/R46270.pdf.

[4] UNDP, "Putting The UN Framework For Socio-Economic Response To Covid-19 Into Action: Insights," Brief Prepared By The United Nations Development Programme (UNDP), 2020. [Online]. Available: https://www.undp.org/content/undp/en/home/coronavirus/socio-economic-impact-of-covid-19.html.

[5] ASEAN Biodiaspora Virtual Center, "Risk Assessment for International Dissemination of COVID-19 to the ASEAN Region," Report generated by ASEAN Biodiaspora Virtual Center (ABVC), 2020. [Online]. Available: https://asean.org/storage/2020/02/COVID-19_Report-of-ASEAN-BioDiaspora-Regional-VirtualCenter_11November2020.pdf

[6] Kementrian Perindustrian Republik Indonesia, "The Ministry of Industry Ensures Industrial Activities and Covid19 Prevention Protocols Can Go Together/Kemenperin Pastikan Kegiatan Industri dan Protokol Pencegahan Covid-19 Dapat Berjalan Beriringan," Official Website of Kementrian Perindustrian Republik Indonesia, 14 April 2020. [Online]. Available: https://kemenperin.go.id/artikel/21679/Kemenperin-Pastikan-Kegiatan-Industri-danProtokol-Pencegahan-Covid-19-Dapat-Berjalan-Beriringan.

[7] Keçeci, Ş., "Risk Perception and Unsafe Behaviors in Occupational Health and Safety," International Journal on Lifelong Education and Leadership, vol. 5, no. 1, pp. 1-4, 2019.

[8] Parihar, DS, and Rahul, M., "A Review on Supply Chain Disruption: Managing Risk," The International Journal of Business \& Management, vol. 2, no. 7, pp. 236-241, 2014.

[9] Chapman, P., et al., "Identifying and Managing Supply Chain Vulnerability," Logistics and Transport Focus, vol. 4, no. 4, pp. 59-70, 2002.

[10] Haghani, M, et al., "The Scientific Literature on Coronaviruses, COVID-19 and Its Associated Safety-related Research Dimensions: A Scientometric Analysis and Scoping Review,” Safety Science, vol. 129, pp. 1-8, 2020, doi: https://doi.org/10.1016/j.ssci.2020.104806

[11] Lemke, MK., Apostolopoulos, Y., And Sonmez, S., "Syndemic Frameworks to Understand the Effects of COVID19 on Commercial Driver Stress, Health, And Safety," Journal of Transport \& Health, vol. 18, pp. 1-5, 2020, doi: https://doi.org/10.1016/j.jth.2020.100877

[12] Adesoye, T., et al., "Optimization of Surgical Resident Safety and Education During the COVID-19 PandemicLessons Learned,” Journal of Surgical Education, 2020, doi: https://doi.org/10.1016/j.jsurg.2020.06.040

[13] Badan Pusat Statistik, "Berita Resmi Statistik," Official Report of Badan Pusat Statistik, 2020. [Online]. Available : https://www.bps.go.id/website/materi_ind/materiBrsInd-20200205114932_.pdf

[14] Cook, TM., "Personal Protective Equipment During the Coronavirus Disease (COVID) 2019 Pandemic-a Narrative Review," Anaesthesia, vol. 75, no. 7, pp. 920-927, 2020. 
[15] Zacharatos, A, Barling, J., and Iverson, RD., "High-Performance Work Systems And Occupational Safety," Journal of Applied Psychology, vol. 90, no. 1, pp. 77-93, 2005.

[16] Donthu, N., and Gustafsson, A., "Effects of COVID-19 on Business and Research," Journal of Business Research, vol. 117, pp. 284-289, 2020.

[17] Umugwaneza, C, Nkechi, IE, and Mugabe, JB., "Effect of Workplace Safety and Health Practices on Employee Commitment and Performance in Steel Manufacturing Companies in Rwanda," European Journal of Business and Management Research, vol. 4, no. 5, 2019.

[18] Jilcha, K, Kitaw, D., and Beshah, B., "Workplace Innovation Influence On Occupational Safety and Health," African Journal of Science, Technology, Innovation and Development, vol. 8, no. 1, pp. 33-42, 2016.

[19] Jilcha, K., and Kitaw, D., "Industrial Occupational Safety and Health Innovation For Sustainable Development", Engineering Science and Technology, an International Journal, vol. 20, issue 1, pp. 372-380, 2017.

[20] Joyce, A and Paquin, RL, "The Triple Layered Business Model Canvas: A Tool to Design More Sustainable Business Models”, Journal of Cleaner Production, vol. 135, pp. 1474-1486, 2016.

[21] Bayram, M., "The Management Commitment to OHS, Employee Satisfaction and Safety Performance: An Empirical Study," International Journal of Latest Engineering and Management Research (IJLEMR), vol. 3, no. 7, pp. 63-71, 2018.

[22] Tawiah, KA., and Mensah, J., "Occupational Health and Safety and Organizational Commitment: Evidence from the Ghanaian Mining Industry," Safety and Health at Work, vol. 7, no. 3, pp. 225-230, 2016.

[23] Kaynak, R., et al., "Effects of Occupational Health and Safety Practices on Organizational Commitment, Work Alienation, and Job Performance: Using the PLS-SEM Approach," International Journal of Business and Management, vol. 11, no. 5, pp. 146-166, 2016.

[24] Wachter, JK., and Yorio, PL., "A system of safety management practices and worker engagement for reducing and preventing accidents: An empirical and theoretical investigation," Accident Analysis \& Prevention, vol. 68, pp. 117-130, 2014.

[25] Ndegwa, PW, Guyo, W., Orwa, G., and Ng'ang'a, R., "The Influence of Management Support in the Implementation of Occupational Safety and Health Programmes in the Manufacturing Sector in Kenya," International Journal of Academic Research in Business and Social Science, vol. 4, no. 9, pp. 490-506, 2014.

[26] Tappura, S., Syvänen, S., and Saarela, KL., "Challenges and Needs for Support in Managing Occupational Health and Safety from Managers' Viewpoints," Nordic journal of working life studies, vol. 4, no. 3, pp. 31-51, 2014.

[27] Nderitu, R, Mwaura, P., and Gichuhi, D., "Management commitment influence on implementation of occupational health and safety policies in water and sanitation companies in Nyeri County, Kenya," International Journal of Research in Business and Social Science, vol. 8, no. 6, pp. 321-330, 2019.

[28] Zwetsloot, GIJM., et al, "The Importance of Commitment, Communication, Culture and Learning for the Implementation of The Zero Accident Vision in 27 Companies in Europe," Safety Science, vol. 96, pp. 22-32, 2017.

[29] Bayram, M., "Safety Training and Competence, Employee Participation and Involvement, Employee Satisfaction, and Safety Performance: An Empirical Study On Occupational Health And Safety Management System Implementing Manufacturing Firms," Alphanumeric Journal - The Journal of Operations Research, Statistics, Econometrics and Management Information Systems, vol. 7, no. 2, pp. 301-318, 2019.

[30] Balkissoon, MN., "Occupational Safety and Health in Organizational Strategy," Global Encyclopedia of Public Administration, Public Policy, and Governance, pp. 1-10, 2016, doi: 10.1007/978-3-319-31816-5_2747-1.

Int. J. Public Health Sci. Vol. 10, No. 1, March 2021: 68 - 76 